\title{
Surgical treatment for locally advanced lung cancer involving the heart and great vessels: a mini-review
}

\author{
Giacomo Argento, Erino Angelo Rendina, Giulio Maurizi \\ Department of Thoracic Surgery, Sant'Andrea Hospital, Sapienza University of Rome, Rome, Italy \\ Contributions: (I) Conception and design: All authors; (II) Administrative support: None; (III) Provision of study materials or patients: All authors; \\ (IV) Collection and assembly of data: All authors; (V) Data analysis and interpretation: All authors; (VI) Manuscript writing: All authors; (VII) Final \\ approval of manuscript: All authors. \\ Correspondence to: Giulio Maurizi, MD. Department of Thoracic Surgery, "Sapienza” University of Rome, "Sant'Andrea” Hospital, Via di Grottarossa, \\ 1035, 00189 Rome, Italy. Email: giuliomaurizi@libero.it.
}

\begin{abstract}
Currently, there is no unanimous agreement about the indications of surgical treatment for locally advanced lung cancer, particularly when the heart and the great vessels are involved. A few reasons for concern emerging in such circumstances. Firstly, the technical difficulties, both from the surgical and anesthesiological point of view, that arise when a vascular resection and reconstruction is required (depending on the anatomical structure which is involved and the extent of involvement), together with the significant increase in intraoperative and postoperative risk for bleeding. Secondly, and perhaps more importantly, the oncological value that such complex operations are intended to provide. Though generally not considered indicated in these cases, surgery can be offered to highly selected patients when a radical resection is considered achievable, and neither distant nor nodal metastasis are present. Throughout the last few decades, many authors have explored the possibility for surgical resection of lung cancer involving the heart and/or the great vessels [these include the thoracic aorta, the pulmonary artery and the superior vena cava (SVC)]. In this article, we consider their experiences focusing on the technical aspects of the vascular reconstruction. In some of these situations the use of the cardiopulmonary bypass may be required as further described.
\end{abstract}

Keywords: Lung cancer; surgery; heart; great vessel

Received: 12 February 2020; Accepted: 28 February 2020; Published: 25 August 2020.

doi: $10.21037 /$ ccts.2020.02.07

View this article at: http://dx.doi.org/10.21037/ccts.2020.02.07

\section{Introduction}

Non-small cell lung cancer (NSCLC) involvement of neighboring structures, particularly the heart and great vessels, is classically considered a relative contraindication for surgical treatment, mainly due to technical considerations, difficulties in achieving a radical resection, concerns regarding perioperative morbidity and mortality, and poor oncological outcomes. However, many authors in the last few decades have reported encouraging shortterm and long-term results in selected patients undergoing lung resection extended to cardiovascular structures. These include the heart (mainly the left atrium), the superior vena cava (SVC), the pulmonary arteries and the thoracic aorta.

\section{Pulmonary artery}

The advantages of pulmonary artery reconstruction after resection for lung cancer involvement are well established. It allows to avoid pneumonectomy thus preserving respiratory function, and it has comparable oncological results with standard lobectomy (1). It might as well be associated with bronchoplastic procedures (2). The choice of the particular reconstruction technique is made intraoperatively on the basis of the extent of vascular involvement. It can be performed by tangential excision with primary suture, usually when less than $25 \%$ of the vascular circumference is involved (3). If a larger portion of the vessel is involved, up to half of the circumference, 


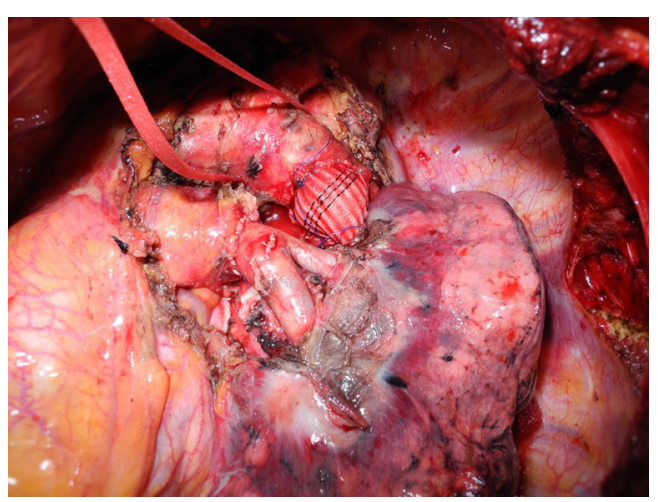

Figure 1 Intraoperative picture illustrating the aortic arch reconstructed with a Dacron patch.

reconstruction may be carried out by partial resection and positioning of a patch to fill the gap; patches may be in autologous, bovine or porcine pericardium, or autologous pulmonary vein. If more than half of the circumference is involved by the tumor, circumferential resection is performed with end-to-end anastomosis or, if the resected segment is too long, interposition of a prosthetic conduit in pericardium or pulmonary vein $(4,5)$. While pulmonary artery sleeve resection has become a relatively common indication in thoracic surgery, resection of the bifurcation of the main pulmonary artery has also been described with the use of cardiopulmonary bypass $(\mathrm{CPB})$, but the indication remains unclear $(6,7)$.

\section{Svc}

Resection and reconstruction of the SVC is a complex procedure (8). Lung cancer invading the SVC frequently involves the bronchial tree, especially the carina, and lobectomy with bronchoplasty or pneumonectomy is frequently necessary to resect such tumors. The SVC might as well be infiltrated by metastatic nodes and this is a negative prognostic factor compared to direct primary tumor invasion (9). Clamping of the SVC leads to an increase of the venous pressure in the cephalic district, with the risk of complications such as intracranial bleeding, cerebral edema and severe reduction of cardiac output, therefore care must be taken in intraoperative management. While clamping of a chronically occluded SVC is better tolerated hemodynamically, it is less likely to be eligible for radical surgery, so patient selection is crucial. Intraoperative management for reducing the risk of hemodynamic imbalance includes fluid implementation via venous catheter in the lower limbs, vasoconstrictive agents, and reducing the clamping time as much as possible. Intravascular or extravascular shunts may be used to reduce the effects of vascular clamping. Intraoperative and post-operative heparinization is mandatory to avoid thrombotic complications. According to the extent of the vascular involvement, the SVC reconstruction can be performed by tangential resection and direct suture or interposition of an autologous or bovine pericardial patch, but the most common procedure is the replacement with a prosthetic conduit, usually in polytetrafluoroethylene (PTFE) or autologous/bovine pericardium $(10,11)$. When the confluence of the innominate veins is infiltrated by the tumor, the preference is to revascularize only one innominate vein, usually the left (12).

\section{Thoracic aorta}

En bloc resection of lung cancer invading the thoracic aorta is another debated issue (13). It is a very delicate and complex procedure and many techniques have been described (14). Although difficult to achieve, radical resection allows good oncological results with reasonable morbidity and mortality rates. The choice of the reconstruction technique is based on the site of invasion (aortic arch or descending aorta), on the circumferential extent and on the depth of the vascular wall involvement. If the aortic infiltration is locally confined to the adventitia and a plane of dissection within the aortic wall can be easily developed, a subadventitial dissection can be conducted after having encircled the aorta below and over the infiltrated area for eventual emergency clamping. When there is evident or suspected invasion of the media layer of the aorta, and more than approximately $30 \%$ of aortic circumference is involved by the tumor, different approaches can be used: direct aortic clamping with aortic wall resection and reconstruction particularly in cases with vascular involvement located at the level of the descending aorta (15). Partial CPB between the femoral vein and femoral artery or a temporary bypass graft from the ascending aorta to the descending aorta can be performed in cases of aortic arch involvement, with the possibility of reconstruction of an infiltrated subclavian artery or carotid artery (16). Alternatively, more recently the pre- or intraoperative aortic endograft placement and aorta/aortic arch resection by the cross-clamping technique have successfully been applied to allow a safe aortic wall dissection, avoiding the use of $\mathrm{CPB}$ $(17,18)$ (Figure 1). 


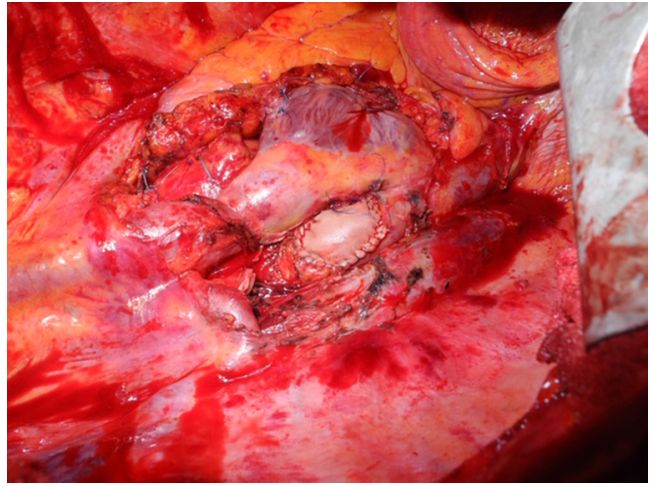

Figure 2 After lung cancer infiltrating the left atrium has been resected, a bovine pericardial patch reconstruction was performed.

\section{Heart}

Although lung cancer with cardiac involvement is usually considered not eligible for surgical treatment, it has occasionally been performed when complete resection was deemed possible and no distant metastasis where present. The indication remains controversial given the very small number of cases reported in literature $(6,7,19-25)$. The majority of described cases concerns left atrium resection. For anatomic reasons, right side tumors can invade the left atrium faster than left tumors because of shorter pulmonary veins. Moreover with left tumors quick multiorgan infiltration (left atrium, aorta, esophagus, etc.) is more common, thus precluding the surgical option. Cardioplegia or fine ventricular fibrillation, used in conjunction with $\mathrm{CPB}$, enables safe opening of the cardiac chambers, which facilitates complete resection of the tumor. Some authors $(19,24,25)$ have described the use of the Sondergaard technique for dissection of the interatrial groove, which allows to lengthen the left atrial cuff, which is then safely clamped, allowing left atrial resection without the use of $\mathrm{CPB}$; the atrial defect can then be directly sutured or a pericardial patch can be interposed to reconstruct the atrial wall (Figure 2).

\section{CPB}

Some of the complex cardiovascular reconstruction procedures described involve the use of $\mathrm{CPB}$. $\mathrm{CPB}$ associated with extended lung resection for cancer has been introduced a long time ago (26), but despite technical advances there are very few cases described, both for a reluctance of surgeons to embrace an aggressive approach to locally advanced lung cancer, and for the concern of major perioperative complications such as bleeding. Interestingly, a meta-analysis from Muralidaran and colleagues (27) concluded that planned use of $\mathrm{CPB}$ gives the best survival benefit compared to its use in an emergency setting for intraoperative complications. In addition, there is the theoretical concern that a combination of CPB-mediated immunosuppression and direct mechanical dissemination could result in systemic spread of the disease during pulmonary resection, though this has never been proved (28).

\section{Conclusions}

Tumors infiltrating the heart and the great vessels are a heterogeneous subset of T4 neoplasms, the treatment of which is still controversial. According to the latest ESMO guidelines (29), patients with biopsy proven T4N0 tumors (stage IIIA) are considered potential surgical candidates if $\mathrm{R} 0$ resection is considered to be achievable. The role of neoadjuvant chemotherapy or chemoradiotherapy is debated (30-32). However, the lack of sufficient randomized data leaves the choice of the treatment to the expertise of lung cancer multidisciplinary teams on a case-by-case basis. With modern advances in surgical techniques and perioperative care, current data suggest a significant improvement over the last few decades in morbidity and mortality of patients undergoing extended resection for tumors invading the thoracic aorta, the pulmonary artery, the SVC and the left atrium. Long-term survival results seem to justify such complex operations, which should therefore be offered to highly selected patients in experienced centers.

\section{Acknowledgments}

We thank Marta Silvi and Carla Conversi for administrative support.

Funding: None.

\section{Footnote}

Provenance and Peer Review: This article was commissioned by the Guest Editors (Francesco Zaraca, Reinhold Perkmann, Luca Bertolaccini and Roberto Crisci) for the series "Thoracic Surgery Without Borders" published in Current Challenges in Thoracic Surgery. The article has undergone external peer review.

Conflicts of Interest: All authors have completed the ICMJE 
uniform disclosure form (available at https://ccts.amegroups. com/article/view/10.21037/ccts.2020.02.07/coif). The series "Thoracic Surgery Without Borders" was commissioned by the editorial office without any funding or sponsorship. EAR serves as an unpaid editorial board member of Current Challenges in Thoracic Surgery from March 2019 to March 2021. The authors have no other conflicts of interest to declare.

Ethical Statement: The authors are accountable for all aspects of the work in ensuring that questions related to the accuracy or integrity of any part of the work are appropriately investigated and resolved.

Open Access Statement: This is an Open Access article distributed in accordance with the Creative Commons Attribution-NonCommercial-NoDerivs 4.0 International License (CC BY-NC-ND 4.0), which permits the noncommercial replication and distribution of the article with the strict proviso that no changes or edits are made and the original work is properly cited (including links to both the formal publication through the relevant DOI and the license). See: https://creativecommons.org/licenses/by-nc-nd/4.0/.

\section{References}

1. Venuta F, Ciccone AM, Anile M, et al. Reconstruction of the pulmonary artery for lung cancer: Long-term results. J Thorac Cardiovasc Surg 2009;138:1185-91.

2. Maurizi G, D’Andrilli A, Venuta F, et al. Bronchial and arterial sleeve resection for centrally-located lung cancers. J Thorac Dis 2016;8:S872-S881.

3. Shrager JB, Lambright ES, Mc Grath CM, et al. Lobectomy with tangential pulmonary artery resection without regard to pulmonary function. Ann Thorac Surg 2000;70:234-9.

4. D'Andrilli A, Maurizi G, Ciccone AM, et al. Long-segment pulmonary artery resection to avoid pneumonectomy: long-term results after prosthetic replacement. Eur J Cardiothorac Surg 2018;53:331-5.

5. D'Andrilli A, Maurizi G, Andreetti C, et al. Pulmonary artery reconstruction with pulmonary vein conduit for lung cancer: medium-term results. Ann Thorac Surg 2014;98:990-5.

6. Park B, Cho JH, Kim HK, et al. Long-term survival in locally advanced non-small cell lung cancer invading the great vessels and heart. Thoracic Cancer 2018;9:598-605.
7. Tsuchiya R, Asamura H, Kondo H, et al. Extended Resection of the Left Atrium, Great Vessels, or Both for Lung Cancer. Ann Thorac Surg 1994;57:960-5.

8. Dartevelle P, Macchiarini P, Chapelier A. Technique of superior vena cava resection and reconstruction. Chest Surg Clin N Am 1995;5:345-58.

9. Suzuki K, Asamura H, Watanabe S, et al. Combined Resection of Superior Vena Cava for Lung Carcinoma: Prognostic Significance of Patterns of Superior Vena Cava Invasion. Ann Thorac Surg 2004;78:1184-9.

10. Venuta F, Rendina E, Furio Coloni G. Lung resections combined with vena cava replacement. Multimed Man Cardiothorac Surg 2017;2017. doi: 10.1510/ mmcts.2004.000141.

11. Maurizi G, Poggi C, D'Andrilli A, et al. Superior Vena Cava Replacement for Thymic Malignancies. Ann Thorac Surg 2019;107:386-92.

12. Spaggiari L, Thomas $P$, Magdeleinat P. Superior vena cava resection with prosthetic replacement for non-small cell lung cancer: long-term results of a multicentric study. Eur J Cardiothorac Surg 2002;21:1080-6.

13. Klepetko W, Wisser W, Birsan T, et al. T4 lung tumors with infiltration of the thoracic aorta: is an operation reasonable? Ann Thorac Surg 1999;67:340-4.

14. Marulli G, Rendina EA, Klepetko W, et al. Surgery for T4 lung cancer invading the thoracic aorta: Do we push the limits? J Surg Oncol 2017;116:1141-9.

15. Wex P, Graeter T, Zaraca F, et al. Surgical resection and survival of patients with unsuspected single node positive lung cancer (NSCLC) invading the descending aorta. Thorac Surg Sci 2009;6:Doc02.

16. Ohta M, Hirabayasi H, Shiono H, et al. Surgical resection for lung cancer with infiltration of the thoracic aorta. J Thorac Cardiovasc Surg 2005;129:804-8.

17. Marulli G, Rea F, Zampieri D, et al. Safe resection of the aortic wall infiltrated by lung cancer after placement of an endoluminal prosthesis. Ann Thorac Surg 2015;99:1768-73.

18. Collaud S, Waddell TK, Yasufuku K, et al. Thoracic aortic endografting facilitates the resection of tumors infiltrating the aorta. J Thorac Cardiovasc Surg 2014;147:1178-82.

19. Galvaing G, Tardy MM, Cassagnes L, et al. Left atrial resection for T4 lung cancer without cardiopulmonary bypass: technical aspects and outcomes. Ann Thorac Surg 2014;97:1708-13.

20. Mu JW, Wang YG, Li J, et al. Surgical results of T4 lung cancer invading left atrium and great vessels. Zhonghua Yi 
Xue Za Zhi 2008;88:383-6.

21. Wang X, Liu T, Yin X. Surgical treatment of IIIb-T4 lung cancer invading left atrium and great vessels. Chin Med J 2010;123;265-8.

22. Spaggiari L, Tessitore A, Casiraghi M, et al. Survival after extended resection for mediastinal advanced lung cancer: lessons learned on 167 consecutive cases. Ann Thorac Surg 2013;95:1717-25.

23. Ratto GB, Costa R, Vassallo G, et al. Twelve-year experience with left atrial resection in the treatment of non-small cell lung cancer. Ann Thorac Surg 2004;78:234-7.

24. Spaggiari L, D'Aiuto M, Veronesi G, et al. Extended pneumonectomy with partial resection of the left atrium, without cardiopulmonary bypass, for lung cancer. Ann Thorac Surg 2005;79:234-40.

25. Tsukioka T, Takahama M, Nakajima R, et al. Surgical outcome of patients with lung cancer involving the left atrium. Int J Clin Oncol 2016;21:1046-50.

26. Neville WE, Langston HT, Correll N, et al. Cardiopulmonary bypass during pulmonary surgery. J Thorac Cardiovasc Surg 1965;50:265-76.

27. Muralidaran A, Detterbeck FC, Boffa DJ, et al. Long-term survival after lung resection for non-small cell lung cancer with circulatory bypass: a systematic review. J Thorac Cardiovasc Surg 2011;142:1137-42.

28. Gillinov AM, Greene PS, Stuart RS, et al. Cardiopulmonary bypass as an adjunct to pulmonary surgery. Chest 1996;110:571-74.

29. Postmus PE, Kerr KM, Oudkerk M, et al. Early and locally advanced non-small-cell lung cancer (NSCLC): ESMO Clinical Practice Guidelines for diagnosis, treatment and follow-up. Ann Oncol 2017;28: iv1-iv21.

30. Martins RG, D'Amico TA, Loo BW Jr, et al. The management of patients with stage IIIA non-small cell lung cancer with N2 mediastinal node involvement. J Natl Compr Canc Netw 2012;10:599-613.

31. Albain KS, Swann RS, Rusch VW, et al. Radiotherapy plus chemotherapy with or without surgical resection for stage III non-small cell lung cancer: a phase III randomized control trial. Lancet 2009;374:379-86.

32. van Meerbeeck JP, Kramer GW, Van Schil PE, et al. Randomized controlled trial of resection versus radiotherapy after induction chemotherapy in stage IIIA-N2 non-small cell lung cancer. J Natl Cancer Inst 2007;99:442-50. doi: $10.21037 /$ ccts.2020.02.07

Cite this article as: Argento G, Rendina EA, Maurizi G. Surgical treatment for locally advanced lung cancer involving the heart and great vessels: a mini-review. Curr Chall Thorac Surg 2020;2:29. 